\title{
Three-dimensional Structures of Crystalline B-cell Granules in Dog Pancreatic Islets
}

\author{
By \\ Yasuaki HOTTA, Yoshio MABUCHI and Nakazo WATARI \\ The First Department of Anatomy, Nagoya City University Medical School, \\ Nagoya 467, Japan \\ -Received for Publication, September 7, 1984 -
}

\begin{abstract}
Key Words: Dog, Insulin, Pancreatic islet, Scanning electron microscope, Transmission electron microscope

Summary: The B-cell granules in the dog pancreatic islets are characterized by unique crystalline bar-like shapes under a transmission electron microscope, but their three-dimensional structure could not be observed by conventional transmission electron microscopy. In this study, the authors analyzed the three-dimensional structure of these crystalline B-cell granules using a scanning electron microscope and a method for the reconstruction from the electron micrographs of serial sections. Under transmission electron microscopy, electron micrographs were taken from tissues cut into serial sections, and the whole shapes of the core of B-cell granules were reconstructed. On the other hand, $2.5 \%$ glutaraldehyde-fixed tissues were treated with the tannin-osmium method of Murakami ${ }^{\text {) }}$, freeze-fractured, coated with Pt-Pd slightly, and then electron micrographed with scanning electron microscope.

From these observations, at least two kinds of three-dimensional shapes were recognized: one is a very peculiar shape obtained as if by slicing the cylinder obliquely. However, the cut surface was oblong, with fairly long, parallel sides. The second shape is that of a rhombic hexahedron, which has been reported already by the authors in the human pancreatic islet B-cells. Moreover, the fine particles were observed on the surface of the cores of B-cell granules, although their characteristics could not be ascertained.
\end{abstract}

It is well known that B-cells in the pancreatic islets have crystalline secreting granules. Lacy et al., Watari and many other investigators have reported a variety of Bcell granules in various animals ${ }^{3,4,9)}$. The present investigators have already reported that one of the three-dimensional structure of B-cell granules is a rhombic dodecahedron, which was observed in snake pancreatic islets using high-voltage transmission electron microscopy, computer simulation technique and a method for the reconstruction of three-dimensional structure from electron micrographs of serial sections ${ }^{10}, 11$ ).

In this study, the three-dimensional structure of the B-cell granules was observed in dog pancreatic islets, in which the B-cells are usually scattered throughout the central region as in other mammals. A majority of crystalline B-cell granules show bar or rhombic shapes surrounded with a limiting membrane within the thin section (about

\footnotetext{
* This experiment was supported in part by Grant-in-Aid for Scientific Research from the Ministry of Education, Science and Culture, Japan (No. 23903).
} 
$100 \mathrm{~nm}$ thick) when observed by transmission electron microscopy, but the threedimensional structure of these granules cannot be analyzed within the thin sections by conventional transmission electron microscopy. Fujita et al. reported the three-dimensional structures of the dog pancreatic islet using scanning electron microscopy, but he did not show the highly magnified images of crystalline B-cell granules ${ }^{2)}$.

In this experiment the three-dimensional structures of crystalline B-cell granules of the dogs were observed with scanning electron microscope and a method for reconstructing the three-dimensional structure from the electron micrographs of serial sections.

\section{Materials and Methods}

1. Experimental animals and general preparations

The pancreatic tissues from male dogs were cut into small pieces and fixed with a 2.5\% glutaraldehyde solution which was regulated at $\mathrm{pH} 7.4$ with $0.1 \mathrm{M}$ phosphate buffer. Tissues were then treated by the tannin-osmium method of Murakami ${ }^{6)}$ for the preservation of the fine structure of crystalline insulin granules. After these procedures, they were freeze-cracked in liquid nitrogen ${ }^{8)}$ and dehydrated through a series of graded ethanols. A critical point dryer (HCP-10, Hitachi Co., Ltd., Japan) was used to avoid the artifacts. For observation by the transmission clectron microscopy, some pancreatic tissues from the animals were fixed with a mixture of $2.5 \%$ glutaraldehyde and $2 \%$ osmic acid, which was regulated at $\mathrm{pH} 7.4$ with a veronal acetate buffer. Following dehydration through a series of graded ethanol solutions, the tissues were soaked in propylene oxide, and embedded in Epon $812^{5}$.

\section{Scanning electron microscopy}

After critical point drying, the tissues were mounted on the sample stage, and a spatter coating with Pt-Pd was performed by an ion-spattering apparatus (IB-3, EikoEngineering Co., Ltd., Japan). Then they were observed under a scanning electron microscope (DS-130, Akashi Seisakusho Ltd., Japan) using a high resolution stage. The accelerating potential used in this study was generally $20 \mathrm{kV}$.

3. A method for the reconstruction of three-dimensional structure from electron micrographs of serial sections

Epon embedded specimens were cut with a diamond knife which was equipped on the ultra-microtome (MT-5000, Porter Blum). The serial sections were mounted on a formvar-coated single hole copper grid $^{1)}$. After doubly stained with uranyl acetate and lead mixture ${ }^{7)}$, observed and electron micrographed with a transmission electron microscope at an accelerating potential of 75 kV (H-500; Hitachi Co., Ltd., Japan).

\section{Conventional transmission electron micro- scopy}

For the observations by conventional transmission electron microscopy, epon embedded specimens were cut with a diamond knife on the ultra-microtome (MT5000 , Porter Blum), and mounted on a conventional 150 mesh copper grid. Double stainings were performed with the same method mentioned above. Slightly thick sections (about $200 \mathrm{~nm}$ thick) were cut to obtain more information, and then observed and electron micrographed with transmission electron microscope at an accelerating potential of $75 \mathrm{kV}$ or 100 kV (H-500; Hitachi Co., Ltd., Japan). 


\section{Results}

1. General observation by transmission electron microscopy

In general, the pancreatic islets of mammals are composed of glucagon-secreting A-cells (about 20-25\%), insulin-secreting B-cells (about 70-75\%), somatostatin-secreting D-cells (about 5\%) and several other types of cells. When observed with transmission electron microscope, there were at least three cell types in the dog pancreatic islets including A-, B- and D-cells. A-cell granules had electron-dense spherical cores and were surrounded with a limiting membrane which usually closely approached the cores, whereas D-cell granules had low electron-dense spherical cores, and the halo between the core and limiting membrane was narrower than that of A-cells. B-cell granules were easily distinguished by their crystalline cores surrounded with a limiting membrane (Fig. 1). Almost all of these crystals showed bar shapes with a crystalline lattice structure whose spaces were about $50 \mathrm{~nm}$ when observed by higher magnification (Fig. 2). A few rhombicshaped crystalline granules were also observed among the bar-shaped ones (Fig. 3).

By these observations using the transmission electron microscope the fine details of these sliced B-cell granules were clearly recognized, but their three-dimensional structures or whole shapes cannot be observed.

\section{Scanning electron microscopy}

By scanning electron microscopy, the three-dimensional structure of the dog pancreatic islets were observed. However, it is impossible to distinguish the glucagon-secreting A-cells from the somatostatin-secreting D-cells by this method, because both cells have similar round granules. On the other hand, insulin-secreting B-cells were easily recognized by their unique granule shapes (Fig. 4). The tissues were freeze-cracked rigidly, so the secreting granules in the B-cells were split into two pieces, and some of them cracked in about the center of the granules, leaving the crystalline cores clearly exposed (Figs. 5-7). Two types of crystalline cores were observed, one appearing like an obliquely sliced cylinder. The cut surface was oblong, with fairly long, parallel sides, but the whole shape was not observed, and the cracked edge seemed to have the rectangular shape of crystals. The other type showed a rhombic surface with some thickness, but it was difficult to suppose the whole shape by only these observations.

Upon close observation, the core of the former crystalline granules revealed fine particles on the surface (arrows in Figs. 5, 6 and 7), although their characteristics could not be ascertained. Figure 11 shows a crystalline granule in a slightly thick section observed with transmission electron microscope (100 kV accelerating potential). Similar fine particles are also scattered on the crystalline core (arrows in Fig. 11).

\section{Reconstruction of three-dimensional structure from electron micrographs of serial sections}

Four to seven electron micrographs from serial sections were used to analyze the three-dimensional structure of crystalline B-cell granules in the dog pancreatic islets (Figs. $8 a-8$, Figs. 9a-9d, Figs. 10a-10e).

By reconstructing one of the whole crystalline granules from seven serial micrographs (Figs. $8 \mathrm{a}-8 \mathrm{~g}$ ), it seemed to have the shape of cut crystals which may be more often observed in the B-cells of the dog under transmission electron microscope, because the probability of these cutting directions are higher than that of the others. Figures $8 \mathrm{a}$ and $8 \mathrm{~g}$ indicate the outside of the granule core, and Fig. $8 \mathrm{~d}$ may be the center of this granule. From this set of micrographs, a model of the crystalline B-cell granules was reconstructed (Fig. $\mathrm{Bh}$ ). If the 
cutting direction is parallel to the surface of the crystalline wide plate, the set of micrographs becomes as shown in Figs. 9a9d. In these micrographs, Fig. 9c contains a large part of the crystal. These cutting models are illustrated in Fig. 9e. Obliquely cut slices are shown in Figs. 10a-10e. The cutting direction is slightly tilted when compared with those in Fig. 8 or Fig. 9. In this set of micrographs, the crystalline core is cut into three parts, and a reconstructed model of the crystalline B-cell granules is shown in Fig. $10 \mathrm{f}$.

From these observations, at least two kinds of whole crystalline shapes were recognized in the B-cell granules of the dog pancreatic islets: one has a very peculiar shape, formed as if by slicing a cylinder obliquely. The cut surface is oblong, with fairly long, parallel sides. The approximate dimensions are as follows: length, $400 \mathrm{~nm}$; width, $250 \mathrm{~nm}$; and thickness, $70 \mathrm{~nm}$. A model of this type of crystal structure was made (see Fig. 12). Although the second shape could not be handled in this experiment by the serial section technique, scanning electron micrographs indicated that the second shape of the crystalline granules might be that of a rhombic hexahedron. A similar shape has been reported already by the authors in the human pancreatic islet B-cell granules ${ }^{9}$.

\section{Discussions}

At first, Lacy observed the B-cells in the pancreatic islet of the dog by transmission electron microscope ${ }^{3)}$, and recognized unique bar-shaped granules within. Since then, these bar-shaped granules were used as a marker to recognize the dog pancreatic B-cells. Until now, it has been believed that the whole shapes of crystalline B-cell granules in the dog pancreas might be that of a disk, although no one could examine it closely. In this experiment, the authors reported that the core of the crystalline insulin granules in the dog pancreatic B-cells was not a simple disk shape, when observed using high resolution scanning electron microscope and a method for the reconstruction of three-dimensional structure with transmission electron micrographs taken from serial sections.

One of the three-dimensional structures of the B-cell granules in the dog pancreatic islets has a very peculiar shape obtained as if by slicing the cylinder obliquely. However, the cutting surface is oblong, with fairly long, parallel sides. Recently, Watari has classified the B-cell granules in the pancreatic islets of certain animals into 12 types according to their cutting shapes ${ }^{9)}$, and the bar-shaped types were contained in those of dog, bat, mole, mouse, monkey and yellow-tail, although it was not ascertained whether their whole shapes are the same. The same author has postulated that one of the bar-shaped crystalline insulin granules in the human pancreatic islets is a rhombic hexahedron when observed in rather thick sections using high voltage electron microscope (1000 kV accelerating potential). Perhaps, the second type of the whole shape of dog pancreatic B-cell granules is a rhombic hexahedron, which was already observed in the human pancreatic B-cells. This shape has been also observed using the scanning electron microscope.

It is postulated that most of the B-cell granules of pancreatic islets in certain animals including human have crystalline structures. In fact, even showing the round core such as found in rat and mouse, the crystalline lattice structures are observed under a high resolution transmission electron microscope. We have also postulated that the B-cell granules showing the crystalline structure are the insulin storage type in which the insulin molecules might be com- 
pactly and stably stored for a long time, and the amorphous-shaped ones may be rather immature granules. In the excreting stage of the B-cells, most granules show an amorphous structure, suggesting that they might be ready to excrete the secretory substance to the outside of the cells, although some granules can be excreted with an intact crystalline core via exocytosis, which has been reported already by the present authors in the islet B-cells of the yellow-tail ${ }^{9)}$.

Some investigators insist that the crystalline structure of the B-cell granules may be an artifact, but the good correspondence between the high resolution transmission electron micrograph of the snake B-cell granules and X-ray diffraction data was demonstrated in the previous study ${ }^{12}$. It was concluded that the crystalline insulin structure of the B-cell granules observed in the electron micrographs are related to the insulin molecule itself without any binding proteins. The crystalline lattice structure within B-cell granules of the dog could not be completely analyzed using highly magnified transmission electron micrographs in the present study, but this analysis will be conducted in the future.

No conclusion could be reached about the characteristics or significance of the fine particles which adhered to the surface of the crystalline granules observed by scanning electron microscopy. Perhaps they are protein particles interposed between the limiting membrane and the crystalline core in the natural condition. However, they might be dried out during the sampling procedure and then adhered to the surface of the crystalline core.

In conclusion, high-resolution scanning electron microscopy is a very useful method to observe the three-dimensional structure in the fields of cell biology. Although both high-resolution scanning electron micro- scopy and a method for the reconstruction of three-dimensional structure from electron micrographs of serial sections were used in this study to observe the crystalline B-cell granules, an improved sampling method for scanning electron microscopy and better scanning electron microscope resolution allow elimination of the serial section method. Although not available for this experiment, the rapid freezing technique could make it possible to observe more natural structures of the B-cell granules in various animals.

\section{References}

1) Bang, B. G. and Bang, F. B.: Graphic reconstruction of the third dimension from serial electron microphotographs. J. Ultrast. Res., 1: 138-146, 1957.

2) Fujita, T., Kobayashi, S. and Serizawa, Y.: Intercellular canalicule system in pancreatic islet. In (Ed. by) Tanaka, K. and Fujita, T.: Scanning Electron Microscopy in Cell Biology and Medicine, pp. 115-117, Excerpta Medica, Amsterdam-Oxford-Princeton, 1981.

3) Lacy, P. E.: Electron microscopic identification of different cell types in the islets of Langerhans of the guinea pig, rat, rabbit and dog. Anat. Rec., 128: 255-267, 1957.

4) Lange, R. H.: Crystalline islet B-granules in the grass snake Natrix natrix (L.): Tilting experiments in the electron microscope. $J$. Ultrastr. Res., 46 : 301-307, 1974.

5) Luft, J. H.: Improvement in epoxy resin embedding methods. J. Biophys. Biochem. Cytol., 9: 409-414, 1961.

6) Murakami, T.: A revised tannin-osmium method for noncoated scanning electron microscope specimens. Arch. histol. jap., 36: 189-193, 1974.

7) Sato, $T$.: A modified method for lead staining of thin sections. J. Electron Microsc., 17: 158, 1968 (in Japanese).

8) Tokunaga, J., Edanaga, M., Fujita, T. and Adachi, K.: Freeze cracking of scanning electron microscope specimens. A study of the kidney and spleen. Arch. histol. jap., 37: 165-182, 1974.

9) Watari, N.: Crystalline structures observed in both the exocrine and endocrine pancreatic 
cells. In (Ed. by) E. Yamada, K. Kurosumi, V. Mizuhira and T. Nagano: Recent Progress in Electron Microscopy of Cells and Tissues. Igaku-Shoin, Tokyo, pp. 109-130, 1975.

10) Watari, N. and Hotta, Y.: One use of the computer calculation for analysis of threedimensional structure of crystalline insulin granules. The Cell, 8(5): 13-20, 1976 (in Japanese).

11) Watari, N. and Hotta, Y.: Three-dimensional structure of crystalline insulin granules as analyzed by high-voltage electron microscopy and computer calculation. In (Ed. by) Fujita, T.: Endocrine Gut and Pancreas. Elsevier Scientific Publishing Company, Amsterdam: pp. 179-184, 1976.

12) Watari, N. and Hotta, Y. and Mabuchi, Y.: Ultrastructural analysis of crystalline structures including insulin and hemoglobin crystals by high resolution electron microscopy. J. Electron Microsc., 32(1): 70, 1983. 


\section{PLATES}




\section{Explanation of Figures}

\section{Plate I}

Fig. 1. Transmission electron micrograph of the dog pancreatic islet. B-cells(B) have the unique bar-shaped crystalline granule cores, and A-cells(A) have electron-dense spherical granule cores. EX: exocrine part. 

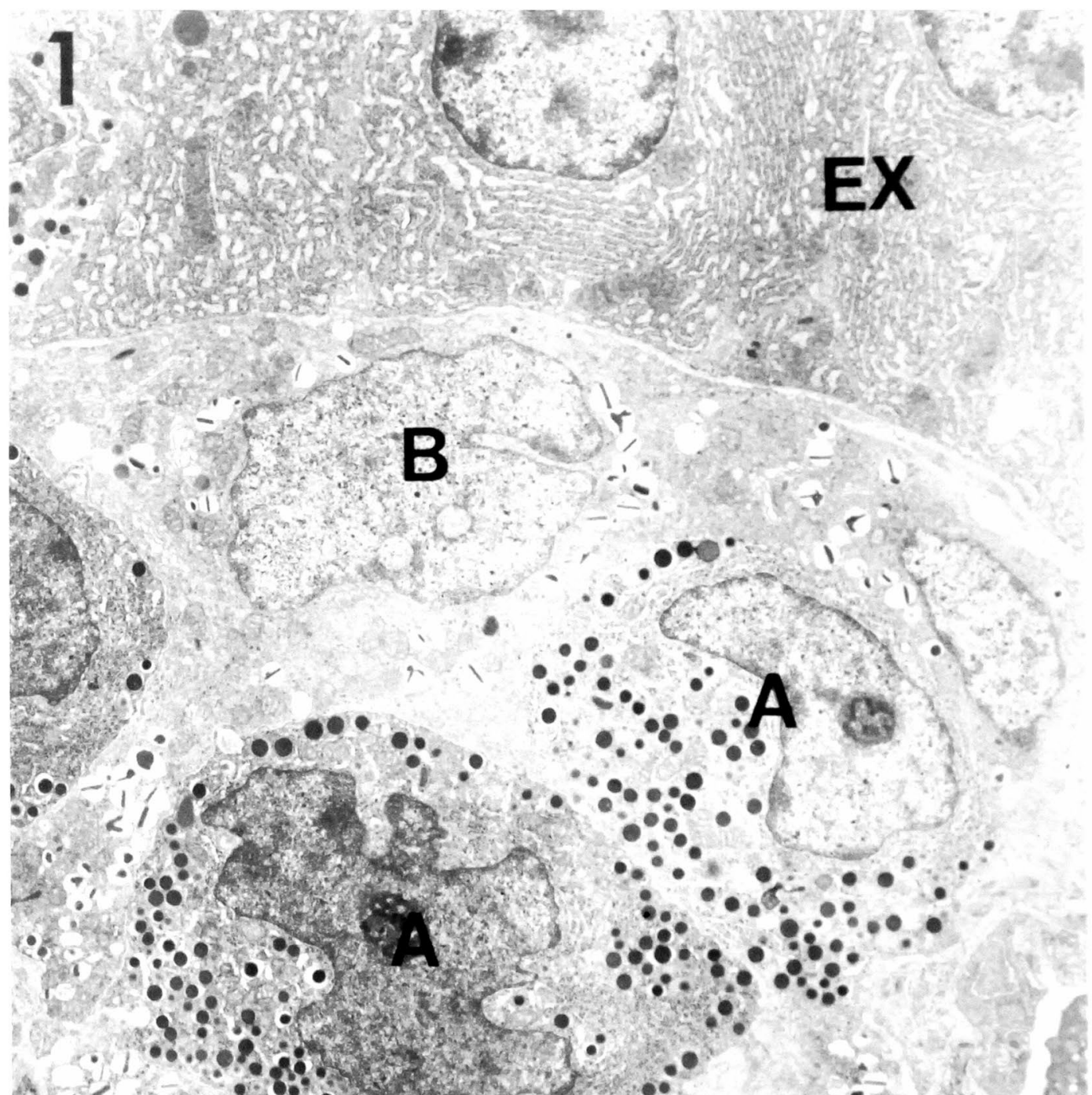

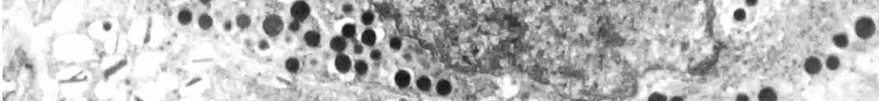

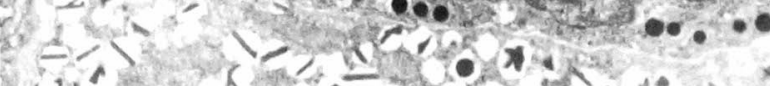

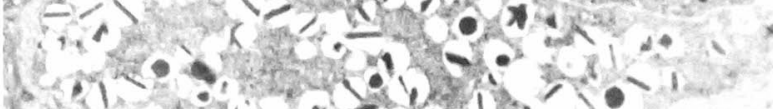

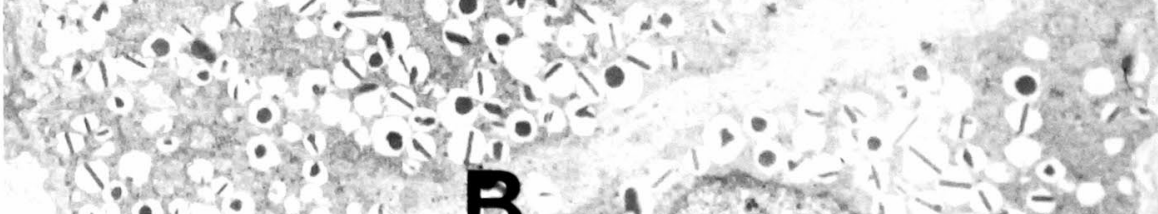

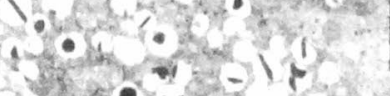

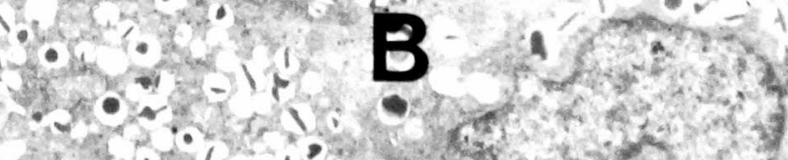

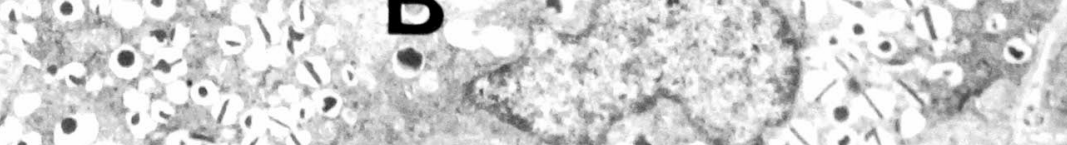

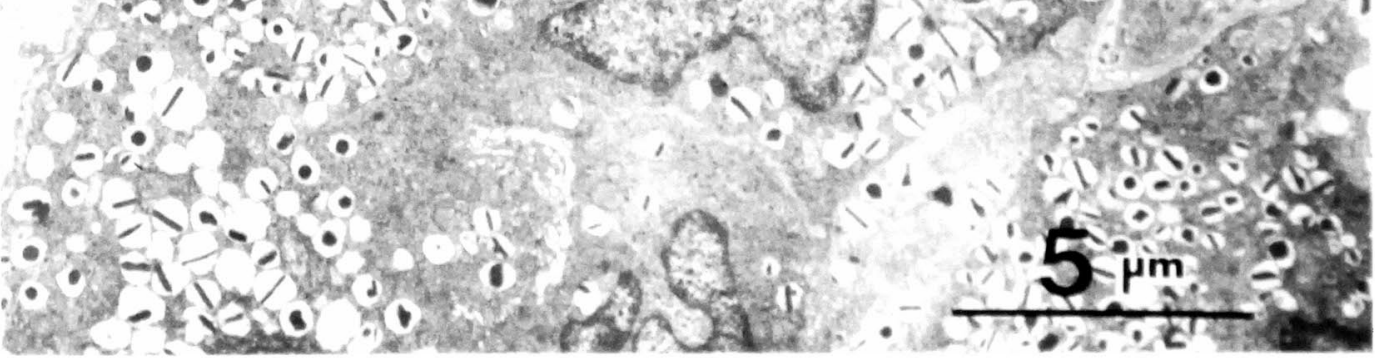




\section{Plate II}

Fig. 2. Highly magnified bar-shaped crystalline B-cell granule in the dog pancreatic islet. Crystalline lattice structure can be seen in this micrograph (arrows), and the periodicity is about $50 \mathrm{~nm}$.

Fig. 3. Highly magnified rhombic crystalline B-cell granules in the dog pancreatic islet. 

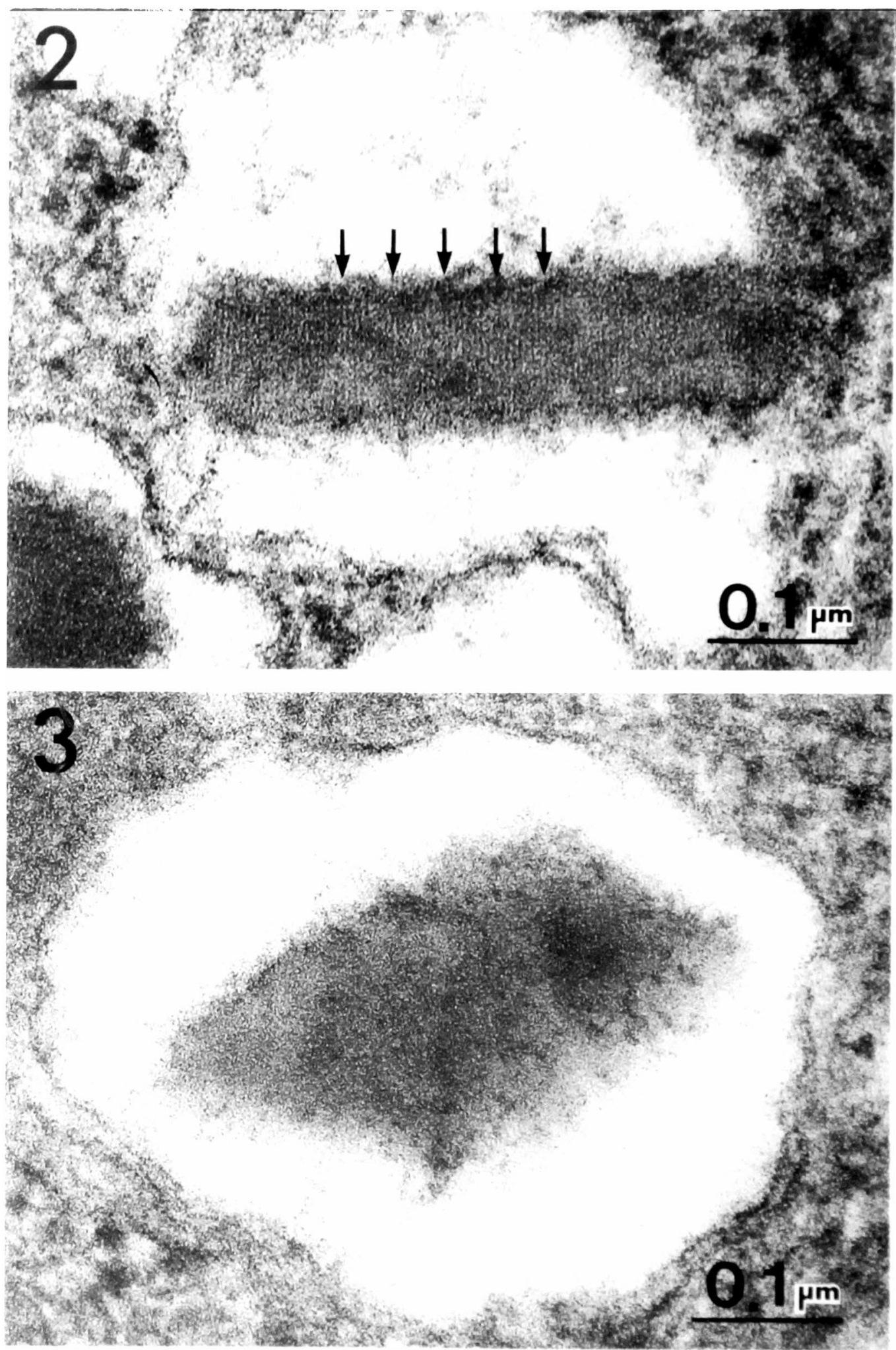


\section{Plate III}

Fig. 4. Scanning electron micrograph of the dog pancreatic islet. B-cells(B) are clearly identified by their crystalline granules. Exocrine cells(EX) have round zymogen granules( $\mathrm{Z})$.

Fig. 5. Scanning electron micrographs of the dog crystalline B-cell granules. A and B indicate the same types of crystalline B-cell granules; $F$ indicates the other types. $\mathrm{H}$ indicates the irregular types of crystalline B-cell granules. The arrows in the micrographs indicate the fine particles on the surface of the crystalline cores. 

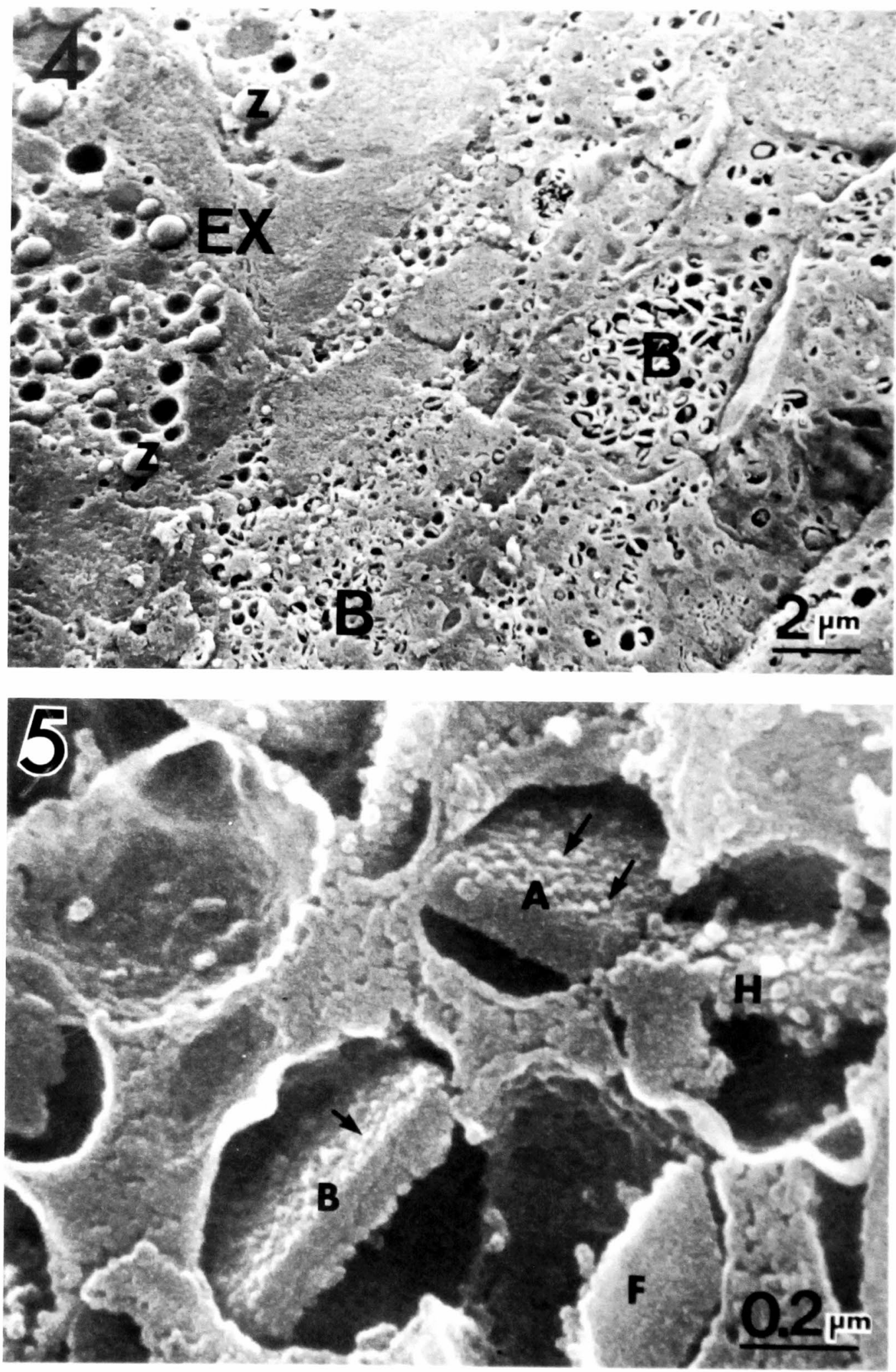


\section{Plate IV}

Figs. 6 and 7. Scanning electron micrographs of the dog crystalline B-cell granules. C in Fig. 6, D in Fig. 7 have almost the same thickness. These are also the same as in A and B in Fig. 5. On the other hand, $E$ is slightly thinner than the others. $E$ is cut on one end, but the other is intact, so it is easy to imagine the whole structure as is illustrated in Fig. 12. G in Fig. 6 indicates the other type of crystalline B-cell granules, which is the same as F in Fig. 5 . I in Fig. 6 and J in Fig. 7 indicate the irregular types of the crystalline B-cell granules, which also same as $\mathrm{H}$ in Fig. 5. The arrows in these micrographs indicate the fine particles on the surface of the crystalline cores. 

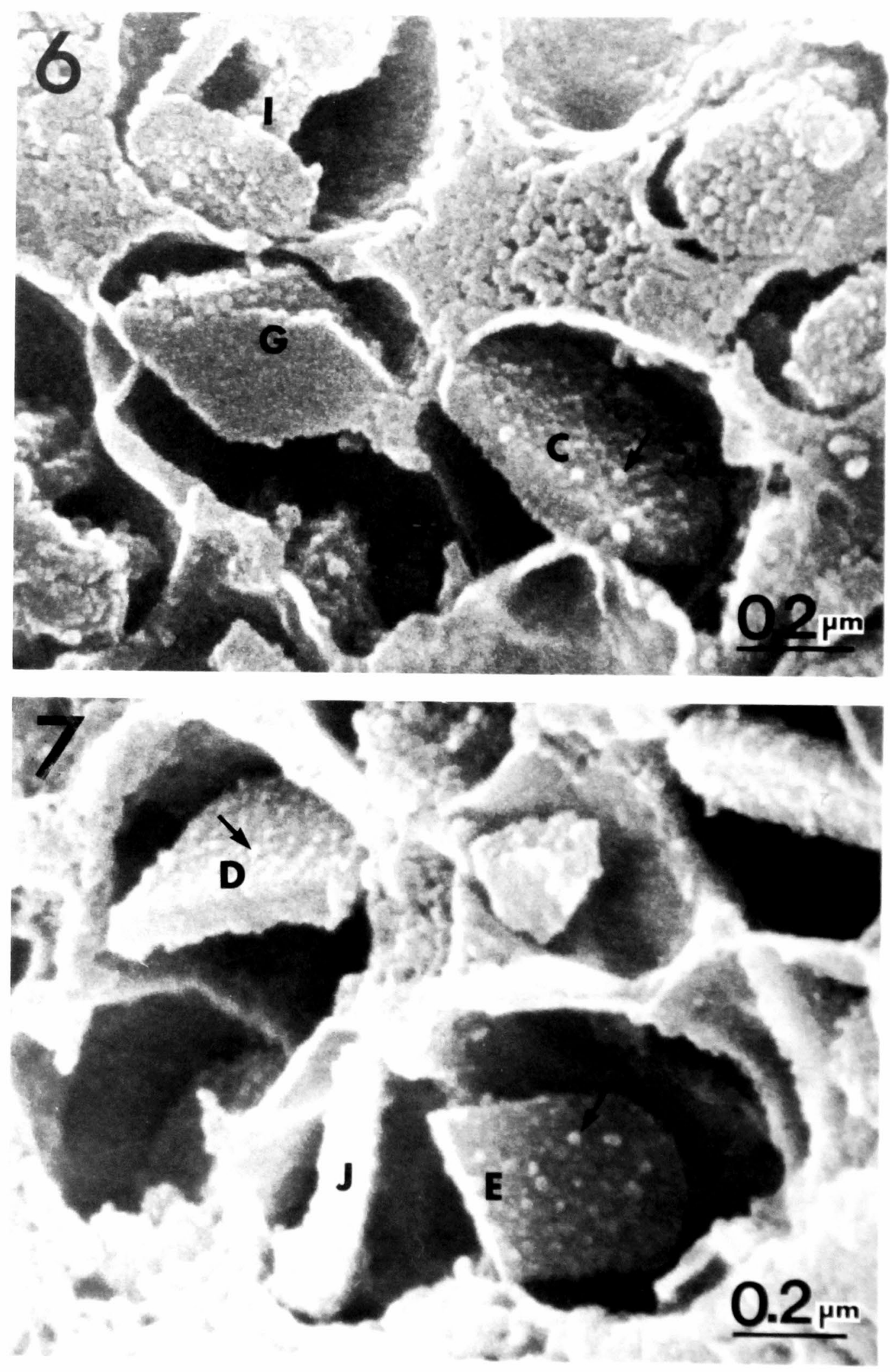


\section{Plate V}

Figs. $8 \mathrm{a}, 8 \mathrm{~b}, 8 \mathrm{c}, 8 \mathrm{~d}, 8 \mathrm{e}, 8 \mathrm{f}$ and $8 \mathrm{~g}$. Seven serial transmission electron micrographs as if cutting a cylinder with a certain thickness. Figures $8 \mathrm{a}$ and $8 \mathrm{~g}$ show the outside of the granule, and Fig. $8 \mathrm{~d}$ shows the center of the granule.

Fig. 8h. A schematic diagram of the crystalline B-cell granules reconstructed from Figs. 8a-8g. 

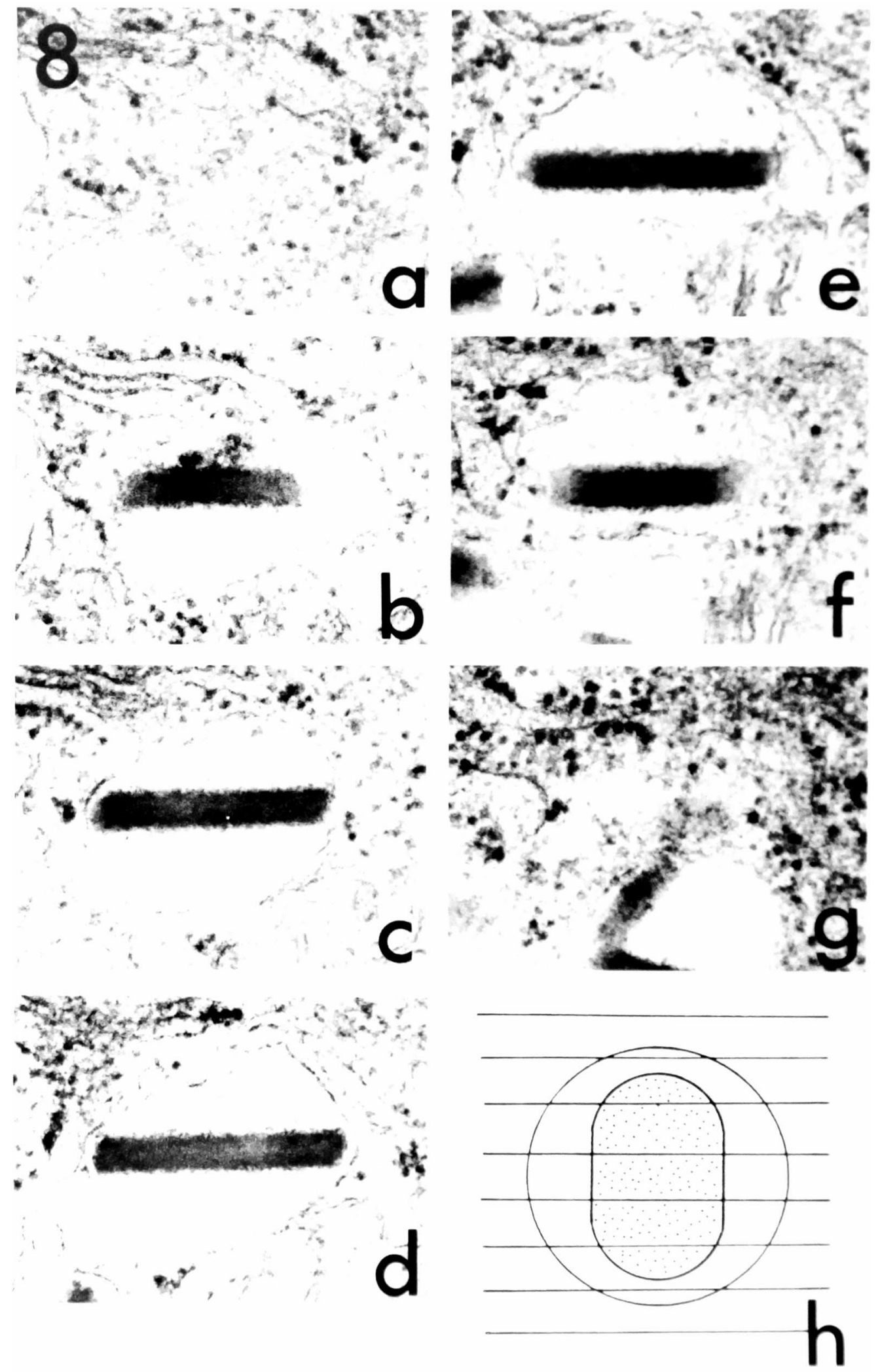


\section{Plate VI}

Figs. 9a, 9b, 9c and 9d. The serial transmission electron micrographs. The crystalline B-cell granules were cut horizontally to the surface of the crystalline plate.

Fig. 9e. A schematic diagram of the crystalline B-cell granules reconstructed from Figs. 9a-9d. 


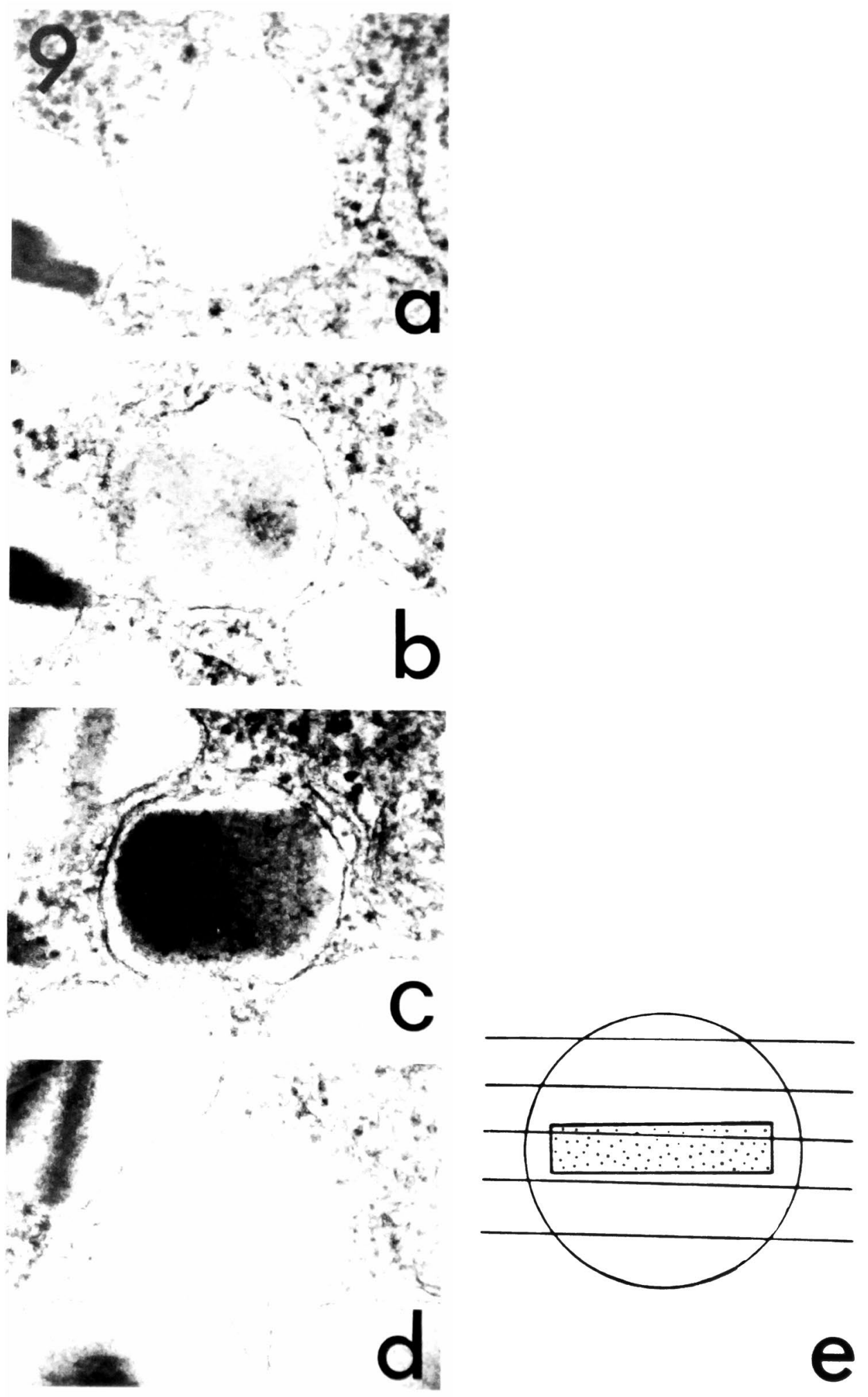




\section{Plate VII}

Figs. 10a, 10b, 10c, 10d and 10e. The serial transmission electron micrographs. The cutting direction of the crystalline B-cell granules is slightly tilted from a perpendicular direction, when these were compared with Fig. 8 or Fig. 9.

Fig. 10f. A schematic diagram of the crystalline B-cell granules reconstructed from Figs. 10a-10e. 


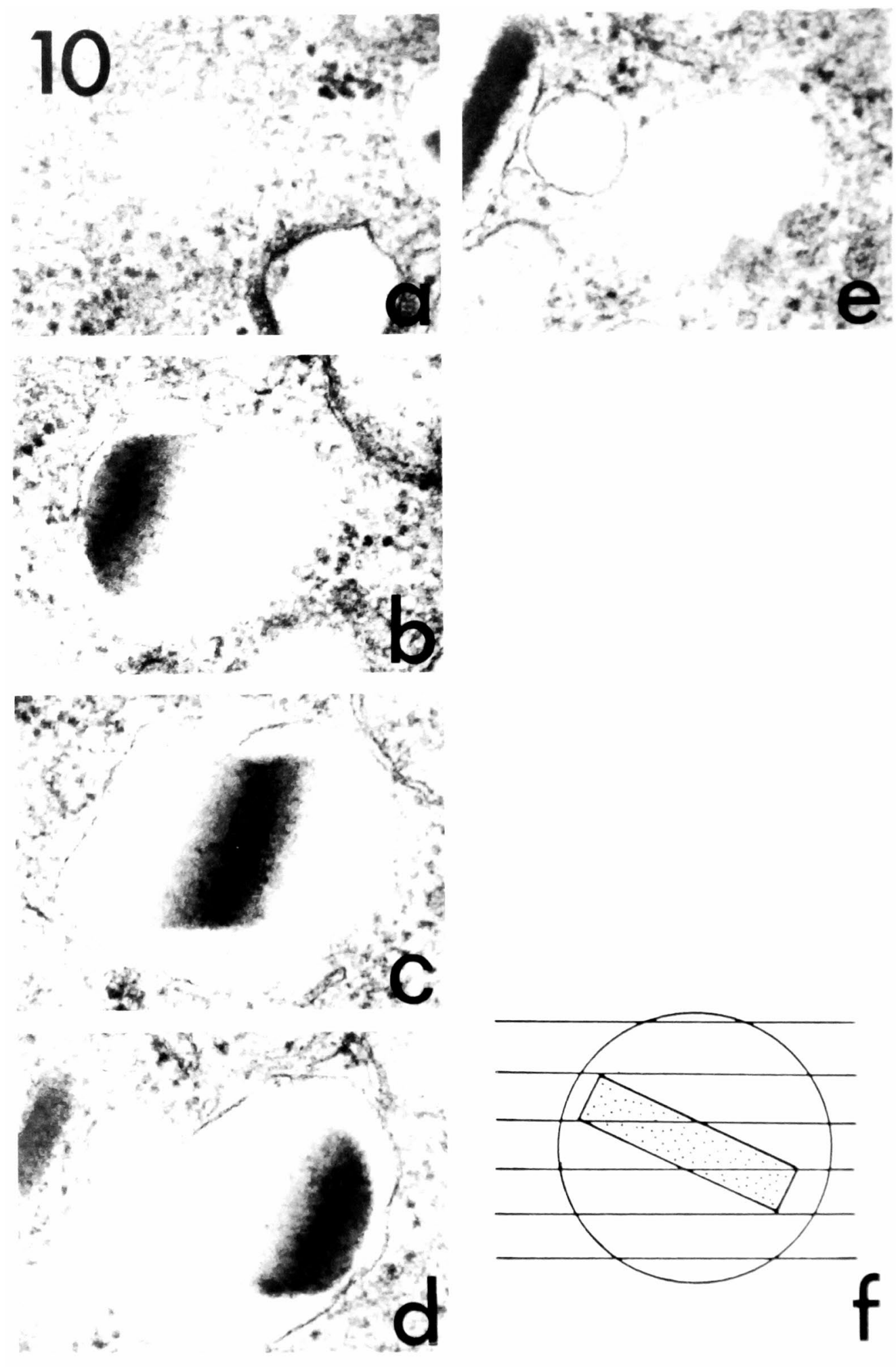




\section{Plate VIII}

Fig. 11. The crystalline B-cell granule from the slightly thick section observed with transmission electron microscope. Arrows indicate the fine particles scattering between the limiting membrane and the crystalline core.

Fig. 12. A model of a crystalline B-cell granule, which has a very peculiar shape as if the cylinder were sliced obliquely; the cut surface is oblong, with fairly long, parallel sides. 


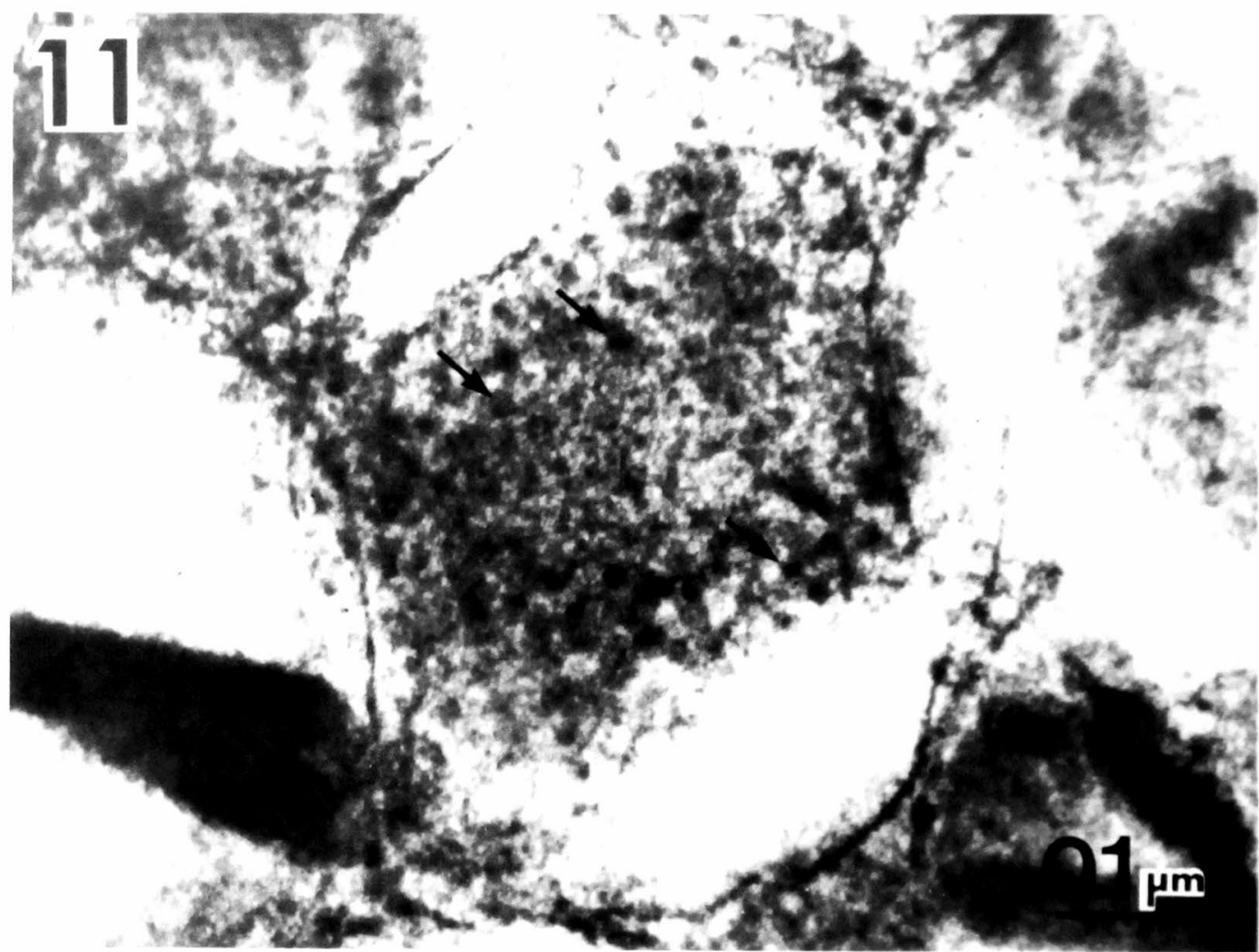

12

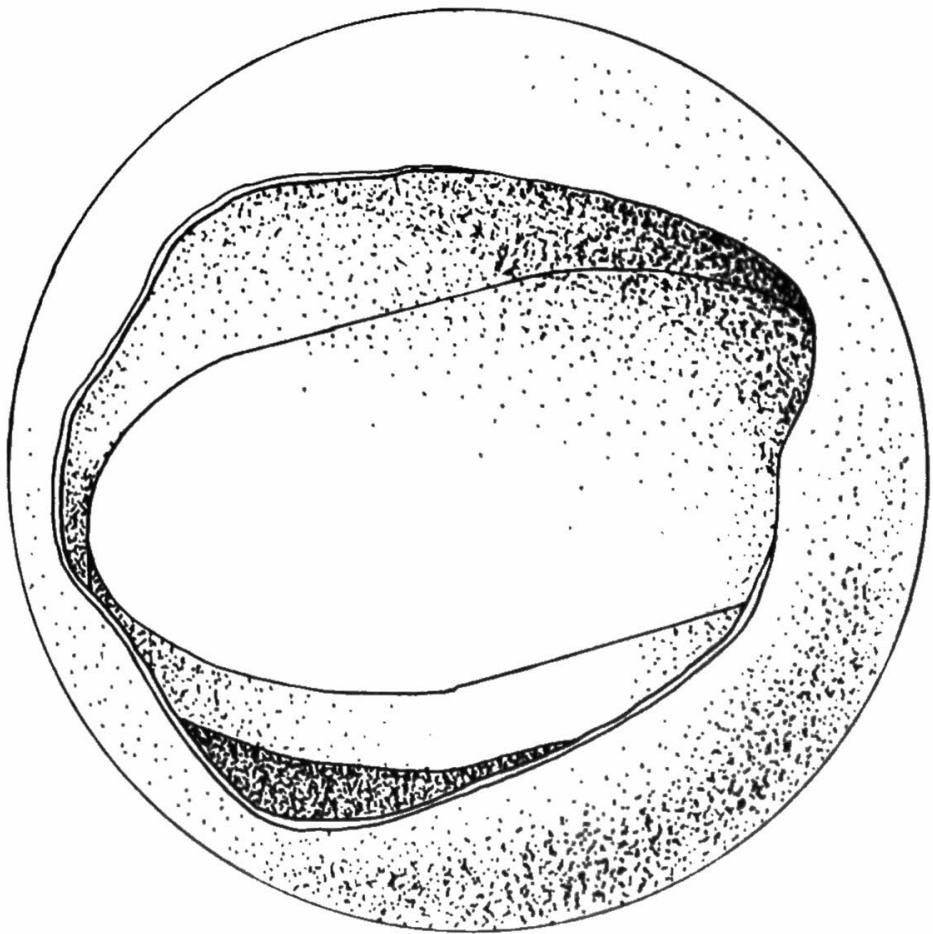

